\title{
Blended Learning: The Possibilities of Benefiting from Others' Experiences and Problems of Implementations at the Lebanese University
}

\author{
Ali Abdalla El-Husseini, Abeer Taha \\ Email address: \\ drali38@hotmail.com (A. A. El-Husseini), abir_taha_77@hotmail.com (A. Taha)
}

Department of English Language and Literature, Faculty of Letters and Humanities, Lebanese University, Beirut, Lebanon

To cite this article:

Ali Abdalla El-Husseini, Abeer Taha. Blended Learning: The Possibilities of Benefiting from Others' Experiences and Problems of Implementations at the Lebanese University. International Journal of HIV/AIDS Prevention, Education and Behavioural Science. Vol. 3, No. 6, 2017, pp. 70-75. doi: 10.11648/j.jhhpebs.20170306.12

Received: October 18, 2017; Accepted: December 19, 2017; Published: January 11, 2018

\begin{abstract}
The inevitable fact is that the revolutionary growth of the Communication and Information Technology (CIT), in a remarkably short period of time, is changing the world, and consequently, the face of education rapidly. In most of the world's modern credible universities, it can be clearly seen that CIT has become an essential element in the teaching-learning process. Not catching up with technology, teaching at the Lebanese University is done in a traditional way from presentation to assessment, and the high percentage of failure in many faculties is not but evidence of the poor quality of learning. Moreover, the curriculum does not take into consideration individual learning styles, which are supposed to have their impact on learning. Furthermore, during the past years, many faculties in several branches (mainly Saida, Beqaa, Tripoli) closed for several reasons and both students' and teachers' time was wasted, and under a lot of time pressure, tried to cover the syllabi by the end of the year. Consequently, this study proposes Blended Learning as a solution to these problems and it tries to explore whether the Lebanese University can benefit from the experiences of other universities implementing Blended Learning. It also addresses the problems the Lebanese University might face in implementing such a program, which is a mix of Distance Education (DE) and classroom teaching despite the fact that itcan improve learning quality at the Lebanese University (LU).
\end{abstract}

Keywords: Blended Learning, Distance Learning, Lebanese University, Communication and Information Technonolgy (CIT)

\section{Introduction}

\subsection{Definition of Blended Learning}

Blended learning is a formal education program in which a student learns at least in part through online delivery of content and instruction with some element of student control over time, place, path or pace [1], [2], [3]. While still attending a "brick-and-mortar" school structure, face-to-face classroom methods are combined with computer-mediated activities [4], [5], [6]. Proponents of blending learning argue that by incorporating the "asynchronous Internet communication technology" into courses serves to "facilitate a simultaneous independent and collaborative learning experience" [7], and this incorporation is a major contributor to student satisfaction and success in such courses. They also cite the opportunity for data collection and customization of instruction and assessment as two major benefits of this approach [8], [9]. Universities with blended learning models may also choose to reallocate resources to boost student achievement outcomes [10].

Higher education institutions all over the world are trying to address changing expectations associated with the quality of the learning experience and the influence of technological innovations on modern education. In a world ruled by the power of information, technology plays a major role in affecting all levels of the various institutions of the society especially the educational institutions which sought to utilize the different tools of technology effectively. In fact, the integration of these crucial concepts shifted the paradigm of education in the 21 st century radically where an answer to any question could come as easy, quick and wide-ranging as in a press-button Google answer. 


\subsection{The Purpose of Promoting Blended Learning}

Blended learning can be an attractive alternative to classroom teaching because it enables universities to expand their course offerings to geographically dispersed students. It allows them to do this without incurring high costs for additional building and new teacher hiring [11], [12]. Furthermore, universities, like LU, that are faced with the pressing problem of a shortage of qualified teachers in some areas may be able to address this problem by utilizing online courses that are readily available from commercial vendors. They can also use technology to broadcast lectures to several classes in different branches at the same time, like using video-conferencing or web-conferencing. These packages are not only easily administered but they can also be easily adjusted and updated more quickly than traditional classroom curricula, offering at least the appearance of providing the most modern and timely instruction possible.

Blended learning can also be a solution to the Lebanese University (LU) problems, academic and national. When the university closes for whatever reasons, students can still take the initiative and exploit their time in learning their subjects in their own time and pace and in the best way that suits their learning styles.

On its Home Page, the LU has this slogan next to its log:

The Lebanese University sees itself as a research university with a strong international orientation. Besides enhancing its disciplinary strengths, the Lebanese University places special emphasis on maintaining the dialogue across traditional subject boundaries. It is the only official institution that gives free higher education to Lebanese citizens in several areas, and this is exactly why it must consider modernization and updating.

The LU has nineteen faculties including distributed over forty six branches located in five geographical districts. The number of students for the academic year 2015-2016 is about 82,000. Its annual budget is 286 million Lebanese Liras, eighty percent of which is spent on teachers' salaries. It followed an old curriculum which was implemented until 2010, when a new one, LMD, was introduced. This new curriculum helped to solve some of the learning problems of the past but remained far from providing a drastic solution since it did not look at the root of the problem.

Teaching is mainly done in the traditional classroom where lectures are delivered to a large audience, sometimes the number jumping over 400, like the case in the Faculty of Letters and the Faculty of Sciences. The academic year consists of two semesters: Fall and Spring. Students' attendance is optional, and more than half the students do not attend their classes. Undergraduates take one final exam in a hall at the end of the semester, through which the students are assessed and passed or failed. Unfortunately the percentage of failures in all faculties is usually high, especially in the first academic year. Also many students quit studying and change majors or go look for a job, if they can find any. This high percentage of failures can indicate one thing; that learning is not taking place as it should. Learners are assessed through that one exam at the end of the semester. Post graduates are assessed in a better way; they take the final exam and a midterm and they have to present a research paper during the semester. In the LU present system, the teacher comes to his lecture, delivers it and goes out with hardly any communication taking place between him/her and their students in and out of the classroom. Students do not have any educational forum or meetings and, in many instances, they do not know each other. Surely, the teacher hardly knows them since there is no direct contact between them in or outside the classroom mainly because of the size of the teaching halls and the huge number of students. Will blended learning not make a perfect way to achieve the goals set by the LU?

Some studies dealing with online education which examined general scores or academic performance have shown that online learning can be just as effective as traditional classroom environments [13], [14], [15], [16], [17]. Other studies which considered learning styles in online education [18] reported that Distance Education suits learners' styles better than traditional classroom learning.

In this study, the central research question was whether the Lebanese University (LU) can benefit from the experiences of other universities that implemented Blended Learning, and what problems might arise from the implementation of such a program at this University. Could Blended learning help modernize the role of the LU to keep up with the demands of education in the 21 st century. Firstly, as mentioned above, when the university closes for any reason, learners can make up for the time lost and do their work at home from a distance and can still interact with their peers and instructors using Communication and Information Technology (CIT). This technology plays a major role in affecting all levels of the various institutions of the society especially the educational institutions which have sought to utilize the different tools of technology effectively. In fact, the integration of these crucial concepts shifted the paradigm of education in the 21 st century radically where an answer to any question could come as easy, quick and wide-ranging as in a press-button Google answer. The promised fiber optic technology recently introduced by the Ministry of Communication will help us a lot by improving the quality and speed of the internet.

Secondly, the introduction of online education as a part of the Blended Learning approach is supposed to contribute to the motivation of instructors and learners alike [19]. It creates more opportunities for teacher/learner interaction which makes both learners and instructors contribute more towards the learning process.

Finally, Blended Learning caters more for an individual's "learning style", which is a key factor in determining which type of educational environment and strategy is best suited to that particular student [20], [21], [22].

Education in Lebanon has had the greatest effect on empowering the human capitals, a valuable commodity, which is highly demanded in neighboring countries for its capabilities and quality knowledge and consequently increasing the Lebanese economic indices. This imposes an obligation on the government to invest in reforming the Lebanese Educational system by re-structuring Education on modern foundations 
among which are: capacity-building, technology and database, participation, efficiency and autonomy [23].

The current status of the High Education in Lebanon is best pronounced by Dr. Baroud and Dr. Abouchedid from Notre Dame University-Louaize (NDU), LEBANON; E-Learning in Lebanon: Patterns of E-learning Development in Lebanon's Mosaic Educational Context Presented in Chapter 18 of E-Learning Practices: Cases on challenges facing E-Learning and National Development edited by Professor Ugur Demiray for Anadolu University, Eskisehir-Turkey [24].

In Lebanon, the concept of virtual universities, Distance education, and Blended Learning does not exist due to restrictive rules and regulations in which the licensing of distance learning or on-line learning programs is not granted by the Ministry of Education and Higher Education (MEHE).

The Arab Open University is a good example of Distance Learning universities established back in 2004 in few Arab countries such as Kuwait, Jordan, Qatar, KSA, Oman and Lebanon. However, students are not encouraged to apply to such a university because its degrees are not universally recognized throughout the region, even in Lebanon, despite the school having one of its branches there and having established quality assurance units in all of its branches [25].

By examining these facts and considering the various hardships facing the Lebanese adults in pursuing their education and living overall, and noting the fact that the Lebanese University is the only Government University in Lebanon, we conclude a concrete reality that Lebanon, and maybe more than any other candidate, is in desperate need to develop Blended Learning concept effectively especially in the higher education institutions in an attempt to compete with the speed light advancement in the world of education and materialize its true role in assisting the new generations to build up a strong future. Many administrators and decision makers though, will raise the question whether Blended Learning could be a feasible choice for the Lebanese University? This study intends to answer this question and recommend adequate approaches to eliminate the challenges of implementation and maybe propose visionary solutions for the bureaucratic barriers which could be encountered during the implementation process.

\section{The Method of Data Collection}

The main research question asked in this study was the following:

Can the LU benefit from BL, and what problems might arise from the implementation of such a teaching method?

The sub-questions can be summarized as follows:

- Can Blended Learning create a better learning environment by creating a community of inquiry?

- Can BL offer its students a wider choice of technology to use in their learning process?

- Can BL help learners and teachers to exploit time wasted because of university closure, whether forcible or otherwise?

- Can BL create more learner motivation, which is supposed to be a crucial factor in the learning process?

- Will students prefer Blended Learning to traditional teaching and, hence, will not mind switching to this new approach?

To answer the above questions, the research design structure involved a descriptive quantitative method. The participants in this study were measured once only, in order to establish the strength of associations between and among the variables. The study aims to determine whether students at the Lebanese University are ready to accept Blended Learning as a new approach to replace the existent traditional one, where teachers are still using the chalk board and recitation for surface knowledge. They were asked whether they believed this new approach can help solving most, or some, of their learning problems. No sophisticated statistics or correlation are necessary for this study, but a straight forward analysis of the learners' responses to the questions in the questionnaire would give a clear idea about the relationship between the variables. Because of the limitations of the sample size and selection process, which employed a non-random convenience sample of available volunteers, this is considered a quasi-experimental research design where the variables (students' opinions and choice of instructional methods), are not believed to be influenced or controlled by the researcher.

\subsection{Population and Sampling}

The participants for this study came from a population of students who were studying English Language and Literature at the Lebanese University. The first and second year 135 students (i.e. Semesters 2 and Four) came from Zahle branch in Beqaa' District where the majority of students came from remote areas like Hasbaya, Rashaya, West beqaa', hermel, etc. So they are believed to have less contact with computers, technology and Internet. The 42 MA students, on the other hand, were studying in Beirut where MA students are placed. The number of the participants (177) was not very big since these were the only students attending classes as attendance at the LU is not a must for their courses. However, the total number of students was significant and representative of the audience for BL. Surely, had the non-attending students participated in the study, results would have been supported more because they would surely go for blended learning since they cannot attend their classes.

\subsection{Data Collection Procedures}

The data was collected over a short period of time in March 2016, after the researcher gained permission from the university and informed consent agreements from the students participating in the study. Students were informed of the purpose of the study and the researchers spent a whole session ( 2 hours) explaining the idea of blended learning. They were then asked to go to the net and get more information if they were interested, and they did. After 2-3 days, questionnaires were administered to the participants to ask them a few questions, whose answers would enlighten the researchers and the readers about the students' expectations on BL. The questionnaires were filled by students in the classroom while the researcher answered any questions concerning them.

The researcher then collected and analyzed the results to determine whether the research questions were answered. 


\subsection{Data Analysis and Ethical Considerations}

After the data were collected, they were tabulated and analysed to determine whether the learners approved to the implementation of BL at their university.

Ethical issues related to equal access, student diversity, surveillance, consent, and confidentiality come to bear on any research involving "virtual" identity and an electronic presence that can easily be simulated [26]. No individual students or teachers were identified in the actual study or in the results, discussion or interviews. The only results are of a descriptive statistical nature. The results of the questionnaire remained confidential and were stored where only the researcher had access to them. Any files on computer are password protected, and files that may identify particular students or lecturers were kept separate from those containing the final compiled results. Based upon the widely accepted understanding of risks to studies with human subjects, however, participation in this study did not place any subjects at personal risk of psychological or physical harm.

The administration of the Lebanese University did not only give permission to the study, but it also encouraged the researcher to go ahead with it to see how feasible it is to implement BL at the LU. All the respondents were first given a brief explanation of the study's purpose and scope, and were invited to read and review the study results upon its completion.

\section{Results}

The main worry of the administration about the implementation of Blended Learning was that the LU Zahle students came mainly from remote areas, and hence, they have no access to pcs or internet. Therefore, they will be against the implementation of the approach in their branch. However, surprisingly, the results do not go in favour of that worry and show that students desperately called for the implementation of the approach to change their state of learning and teaching.

The following tables summarise the responses of the students in the survey. Table 1 shows the number of students who have access to a Pc and Internet. All MA students have access to both $\mathrm{Pc}$ and Internet, while some students in the first and second years have no access to either Pc or net. This is not surprising because of the level of the students; MA students are required to do research and type assignments, so they all have Pcs or laptops. They also have permanent access to Internet.

Table 1. The number of students who have access to Internet and Pc; all levels.

\begin{tabular}{lllllllll}
\hline & 1st yr & \multicolumn{3}{c}{ 2nd yr } & \multicolumn{2}{c}{ Master M1 } & total \\
\hline & Yes & No & Yes & No & Yes & No & Yes & No \\
\hline net & 68 & 5 & 58 & 4 & 42 & 0 & 168 & 9 \\
Pc & 70 & 4 & 58 & 3 & 42 & 0 & 173 & 4 \\
\hline
\end{tabular}

Table 2. The opinion of first year students concerning the implementation of B $L$.

\begin{tabular}{lllll}
\hline Strongly Agree & Agree & Yes & Disagree & Strongly Disagree \\
\hline 38 & 18 & 13 & 3 & 2 \\
37 & 17 & 14 & 6 & 0 \\
39 & 15 & 14 & 6 & 0 \\
\hline
\end{tabular}

Table 2 shows first year students' responses to questions 2 , 3 and 4 . In response to question 2, it shows that 69 students already use the net and 1 does not. It also shows that 68 students like the idea of Blended Learning to an extent ranging between 37 strongly agree, 17 agree and 14 yes. Only 6 students disagree. In response to question 4, most students (68) agree to work from a distance using Blended Learning while 6 students disagree.

Table 3 summarises Semester 4 students' responses to questions 2,3 , and 4 . It shows that 60 students already use the net. 59 students like the idea of BL, and all 61 students do not mind to work from a distance using BL.

Table 3. The opinion of semester 4 students concerning the implementation of $B L$.

\begin{tabular}{lllll}
\hline Strongly Agree & Agree & Yes & Disagree & Strongly Disagree \\
\hline 30 & 7 & 13 & 1 & 0 \\
29 & 19 & 11 & 2 & 0 \\
24 & 15 & 22 & 0 & 0 \\
\hline
\end{tabular}

Table 4 below summarises MA students' responses to questions 2, 3, and 4. It shows that all 42 students already use the net. 41 students like the idea of BL, and all 42 students do not mind to work from a distance using BL.

Table 4. The opinion of MA students concerning the implementation of BL.

\begin{tabular}{lllll}
\hline Strongly Agree & Agree & Yes & Disagree & Strongly Disagree \\
\hline 22 & 11 & 9 & 0 & 0 \\
13 & 12 & 16 & 1 & 0 \\
16 & 9 & 17 & 0 & 0 \\
\hline
\end{tabular}

These results are not surprising. In the 21 st century, the era of social networking and globalisation, the majority of people are expected to have Internet at home or use it on their mobiles or in cafes.

Table 5 shows the total no of students' opinions of all levels together with their percentages. It shows that 87.5 of the students use the net, 89.05 like the idea of the implementation of Blended Learning at the LU, and 86.6 would like to do their work from a distance using Blended Learning.

This survey represents the students who attended classes and were there when the questionnaires were administered. Obviously, one can argue that those who do not attend could very likely vote for the implementation of Blended Learning since they can not or do not attend classes anyway.

Table 5. Total students' opinions concerning the implementation of BL.

\begin{tabular}{lllll}
\hline Strongly Agree - \% & Agree- \% & Yes - \% & Disagree- \% & Strongly Disagree \% \\
\hline $34 \%$ & $39 \%$ & $13.2 \%$ & $9.8 \%$ & $2.4 \%$ \\
$30 \%$ & $28 \%$ & $37 \%$ & $4.2 \%$ & $0.8 \%$ \\
$15.5 \%$ & $17.5 \%$ & $57 \%$ & $7 \%$ & $3 \%$ \\
\hline
\end{tabular}


These figures show that students prefer Blended Learning to traditional teaching and, hence, would not mind switching to this new approach". Most of the students also reported that they have access to Pcs and Internet. The students also reported that they will be quite willing to study using BL and they expected it to be interesting, motivating and a sort of solution to their problems, mainly attendance. However, one year after the implementation of $\mathrm{BL}$, one can evaluate its effectiveness and draw conclusions after obtaining the students' and teachers' feedback on implementation of the approach.

\section{Discussion}

This study was motivated by the recent developments in pedagogical theory and the increase in the number of institutes and students using Blended Learning. It was particularly motivated by three factors. First, some branches of the Lebanese University (especially 3, 4 and 5) closed for a few weeks forcibly because of trouble and tense security situation or because of weather conditions. Second, the number of failures is high at most branches, and it is believed that this is due to focus on surface learning and memorization. Once the students take their exams, they start to forget the material straight afterwards. Third, the Lebanese University needs some modernization, and the researcher argue that the implementation of Blended Learning will solve many of these problems by encouraging the learners to take the initiative and be responsible for their own learning; the job of the teacher here is advising and helping rather than teaching. The creation of a proper learning environment by creating a community of inquiry searching for information is a better choice for learning than the traditional classroom practices applied by teachers. See [27], [28]. The results of this study show that learners at all levels are in favour of Blended Learning, and they have access to the technology needed for its implementation. However, talking to the LU teachers involved in this study reveal that they are not in favour of Blended Learning. At the Ba level, this can be understood and probably justified since there are huge numbers of students in each level (200-400 students in each class). This makes it nearly impossible for a teacher to implement $\mathrm{BL}$ at $\mathrm{Ba}$ level using CIT and emails. Nevertheless, BL can be implemented in the MA classes since there are 18-28 students only in each class, which in turn makes it easy for a teacher to communicate with these students by email and using CIT.

The inevitable fact is that the revolutionary growth of the Communication and Information Technology (CIT), in a remarkably short period of time, is changing the world, and consequently, the face of education rapidly. In most of the world's modern credible universities we can clearly see that CIT has become an essential element in the teaching-learning process. The arrival of the digital technology and Internet to the commercial markets introduced several key changes to the world of education introducing Blended Learning. Blended Learning nowadays is being on demand more and more everyday. American University of Dubai (AUD) and American University of Kuwait (AUK) now require professors especialised in Blended Learning. According to Willis:

The educational world is changing rapidly. We are seeing the use of the Internet and communications and Information Technology (CIT) becoming an important part of learning and teaching strategies of many universities. Some are seeking to become global, virtual institutions, others are using the internet as part of a mixed economy, combining traditional modes of delivery with online teaching. [29].

This might be called the Big Bang theory of Blended Learning. You will hear enthusiastic talk about two way communication between teacher and student replacing the old one way systems of print, radio and television. At last students everywhere will be able to share massive knowledge stores studying in their own time and pace. You may also hear gloomy comments about limited access, costs and the dangers of technological determinism. You may even hear critics who seriously decry the commodification of knowledge represented by Blended Learning. And, of course, there will be cautious optimists who advocate slow but steady advance, but not at any price. [30]

\section{Conclusion}

Based on the findings and the discussion in this study, the following conclusions can be drawn:

1. The Blended Learning approach is doing very well in many developed and developing countries, so there is no reason why it should not motivate LU learners and administration to implement it at least at the MA level.

2. Before the implementation of BL, the approval of the learning audience is extremely important [16]. The students in this study are the audience, and they agreed to the implementation of the approach and thought it was more motivating than traditional classroom teaching which relies heavily on memorization and reciting using surface, not deep, learning. The administration could rely on new teachers who would like to join the university to train them properly for Blended Learning or hire teachers who are already familiar with it.

3. The results of this study are tentative and prospective, so the approach must be properly evaluated after implementation to have a clear picture of the results.

Higher education institutions must address changing expectations associated with the quality of the learning experience and the wave of technological innovations. Participants in the higher education enterprise are questioning traditional approaches and whether they are achieving the high levels of learning promised. Deep and meaningful learning experiences are best supported by actively engaged learners [31]. In this case, the Lebanese University professors should be encouraged to think of this, and the LU administration must take it seriously if it is thinking of the development and improvement of the learning environment. 


\section{References}

[1] Abouchedid, K. \& Eid, G. (2004). E-learning Challenges in the Arab World: Revelations from a Case Study Profile. Quality Assurance in Education Journal, Vol. 12 (1).

[2] Al-Khalifa, H. (October 2009). The State of Distance Education in Saudi Arabia. E-Learn Magazine. Retrieved $18 / 04 / 2017$.

http://elearnmag.acm.org/archive.cfm?aid=1642193

[3] Arbaugh, J. B. (2000). Virtual classroom versus physical classroom: An exploratory study of class discussion patterns and student learning in an asynchronous Internet-based MBA course. Journal of Management Education, 24(2), 213-233.

[4] Baroud, F., Abouchedid, K. (2010) E-Learning in Lebanon: Patterns of E-learning Development in Lebanon's Mosaic Educational Context" in E-Learning Practices, edited by Professor Dr. Ugur Demiray, ISBN 978-975-98590-8-4.

[5] Blomeyer, R. (2002). Online learning for K-12 students: What do we know now? North Central Regional Educational Laboratory. Available at http://www.ncrel.org/tech/elearn/synthesis.pdf

[6] Brown, J. S., \& Duguid, P. (2000). The social life of information. Boston, MA: Harvard Business School Press.

[7] Caperton, H. I. (2012) Learning to Make Games for Impact. The Journal of Media Literacy, 59(1), 28-38.

[8] Collins, S. (2003). Filling educational gaps with online learning: An educationally, economically sound solution. Technological Horizons in Education, 30(6), 42-43.

[9] El-Amin, A., (2004), "Educational reform: 9 principles \& 5 issues) in Options for Lebanon edited by Nawaf Salam, Center for Lebanese Studies oxford publishing services.

[10] Ellis, R. A., Goodyear, P., Prosser, M., \& O'Hara, A. (2006). How and what university students learn through online and face-to-face discussion: Conceptions, intentions and approaches. Journal of Computer Assisted Learning 22(4), 244-256.

[11] Fallah, M. H. \& Ubell, R. (2000) Blind scores in a graduate test: Conventional compared with web-based outcomes. ALN Magazine, 4(2).

[12] Garrison, D. R. (2011, 20 May). E-Learning in the 21st Century: A Framework for Research and Practice. New York: Taylor \& Francis.

[13] Garrison, D. R. and Vaughan, N. D. (2008). Blended Learning in Higher Education: Framework, Principles and Guidelines, $1^{\text {st }}$ edition. New York: Taylor and Francis.

[14] Jacob, A. M. (2011). Benefits and barriers to the hybridization of schools, Journal of education policy, planning, and administration, 1 (1), pp.61-82.

[15] Keegan, D., (1990), Foundations of Distance Education, London, Rutledge.

[16] Kuh G, \& Hu S. (2005). Learning productivity at research universities. Journal of Higher Education 721(1):1-28.

[17] Lockwood, f. and Anne Gooley Eds. (2001). Innovation in Open and Distance Learning: Successful Development of Online and Web-Based Learning. London: Kogan Page.

[18] Maki, R. H., Maki, W. S., Patterson, M., \& Whittaker, P. D. (2000). Evaluation of a web-based introductory psychology course. Behavior Research Methods, Instruments, \& Computers, 32, 230-239.

[19] McKenzie, O., (1975), "Open Learning” in Keegan, D., (1990), Foundations of Distance Education, London, Rutledge.

[20] Moore, M. G. (Ed.) (1990). Contemporary issues in American Distance Education. Elmsford, NY: Pergamon.

[21] Moore, M. G. (2007). Handbook of Distance Education, $2^{\text {nd }}$ edition. London: LEA.

[22] Rowntree, D. (1992). Exploring Open and distance Learning. London: Kogan Page.

[23] Rowntree, D. (1994). Preparing Materials for Open, Distance and Flexible Learning. London: Kogan Page.

[24] Simonson, M., Schlosser, L., (2010), Distance Education, Definition \& Glossary of terms, $3^{\text {rd }}$ edition, IAP - Info age Publishing, Inc.

[25] Staker, H and Horn, M. B. (2015). Blended: Using Disruptive Innovation to Improve Schools. San Francisco: Wiley.

[26] Anderson, B. and Simpson, N. (2005). History and Heritage in distance Education. Journal of Open, Flexible, and Distance Learning, 16, (2).

[27] Strauss, V. (2012). Three fears about blended learning. The Washington Post, 22 Sept.

$\mathrm{http} / / /$ www.washingtonpost.com/blogs/answer-sheet/post/thre e-fears-aboutblended-learning/2012/09/22/56af57cc-035d-11e 2-91e7-2962c74e7738_blog.html. retrieved on 16 June 2017.

[28] Tawil, H. (2008). Comparing Online and Classroom Students with the Kolb Learning Styles Inventory. Unpublished Thesis. North Central University. USA.

[29] Willis, B. (1992), Effective Distance Education: A primer for faculty and administrators, Monograph series in Distance Education 2.

[30] White, M (1982). "Distance education in Australian higher education - a history". Distance Education 3 (2): 255-278.

[31] Windham, C. (2005). Father Google \& mother IM: Confessions of a Net Gen learner. EDUCAUSE Review, 40(5), 42-58. 